\title{
A MINI REVIEW ON THE BASIC KNOWLEDGE ON TENDON: REVISITING THE NORMAL \& INJURED TENDON
}

\section{Tan $S L^{1}$, Selvaratnam $L^{2}$ and Ahmad TS ${ }^{1}$}

1 Tissue Engineering Group (TEG), National Orthopaedic Centre of Excellence for Research and Learning (NOCERAL), Department of Orthopaedic Surgery, Faculty of Medicine, University of Malaya, Kuala Lumpur, Malaysia.

2 School of Medicine \& Health Sciences, Monash University, Sunway Campus, Selangor, Malaysia.

\author{
Correspondence: \\ Tan Sik Loo \\ Tissue Engineering Group, \\ National Orthopaedics Centre of Excellent Research \& Learning (NOCERAL), \\ Departments of Orthopaedic Surgery, Faculty of Medicine, \\ University of Malaya, 50603 Kuala Lumpur, Malaysia \\ Telephone: +603-7967 7548 \\ Fax: $+603-79677536$ \\ E-mail: tansikloo@yahoo.com; tansikloo@gmail.com
}

\begin{abstract}
Tendon is a dense connective tissue that connects muscle to bone. Tendon can adapt to mechanical forces passing across it, through a reciprocal relationship between its cellular components (tenocytes and tenoblasts) and the extracellular matrix (ECM). In early development, the formation of scleraxis-expressing tendon progenitor population in the sclerotome is induced by a fibroblast growth factor signal secreted by the myotome. Tendon injury has been defined as a loss of cells or ECM caused by trauma. It represents a failure of cells and matrix adaptation to mechanical loading. Injury initiates attempts of tendon to repair itself, which has been defined as replacement of damaged or lost cells and ECM by new cells or new matrices. Tendon healing generally consists of four different phases: the inflammatory, proliferation, differentiation and remodelling phases. Clinically, tendons are repaired with a variety of surgical techniques, which show various degrees of success. In order to improve the conventional tendon repair methods, current tendon tissue engineering aims to investigate a repair method which can restore tissue defects with living cells, or cell based therapy. Advances in tissue engineering techniques would potentially yield to a cell-based product that could regenerate functional tendon tissue.
\end{abstract}

Keywords: Cell based therapy, cell differentiation, expression profile, orthopaedics, stem cell biology, tendon tissue engineering

\section{STRUCTURE AND FUNCTION OF NORMAL TENDON}

\section{A. Tendon, Tenocyte and Tendon Extracellular Matrix}

Tendon is dense connective tissue which connects muscle to bone and allows transmission of forces generated by muscle to bone, resulting in joint movement. It is living tissue with mechanical adaptation ability that allows it to respond to mechanical forces (eg. high tensional loading). This is achieved through changes in the metabolism as well as its structural and mechanical properties (1-3). These critical biological and biomechanical roles of tendon are played through a reciprocal relationship between its two main components, i.e. cells and extracellular matrix (ECM) (Table 1).

The overall cell content in tendon tissue is low (20\%). Tenocytes and tenoblasts are the two main cell types which coexist in tendon. Both of these cells are of mesenchymal origin and they constitute about $90-95 \%$ of the cellular component of tendons (4). Tenoblasts are immature tendon cells. They are spindle-shaped and have numerous cytoplasmic organelles. The high organelle content reflects their high metabolic activity. As they mature, tenoblasts become elongated and transformed into tenocytes. Tenocytes have lower nucleus-to-cytoplasm ratio than tenoblasts. These cells lie between the collagen fibers along 
Table 1: Structural compositions of tendon $(1,7)$.

\begin{tabular}{|c|c|}
\hline Component & Total (\%) \\
\hline I. Cellular materials & $\mathbf{2 0}$ \\
\hline i. Tenocytes and tenoblasts & $90-95$ \\
\hline ii. Others (Chondrocytes, synovial cells and vascular cells) & $5-10$ \\
\hline II. Extracellular matrix (ECM) & $\mathbf{8 0}$ \\
\hline i. Water & $60-80$ \\
\hline ii. Dry mass & $20-40$ \\
a. Collagen & $75-85$ \\
Type-I & \\
Type-III and V & \\
Others (Type II, VI, IX, X and XI) & T-5 \\
b. Ground substance (Proteoglycan, glycoproteins and etc.) & Trace amount \\
\hline
\end{tabular}

the long axis of the tendon (5). The remaining $5-10 \%$ of the cellular elements of tendon consists of chondrocytes at the bone attachment and insertion sites (6), synovial cells of the tendon sheath, and vascular cells, including capillary endothelial cells and smooth muscle cells of arterioles (7). Recently, several studies have shown that multipotent tendon stem cells/tendon progenitor cells (TSC/TPC) also exist in human and animal tendon tissues (810). Nevertheless, it remains unclear whether the TSC/TPC are the same population of cells as the tenoblast. It is also unclear whether the tenoblast is a committed tenogenic progenitor cell and whether these cells are different from TSC/TPC. At this point there are no known cell markers to differentiate between the tenocyte, tenoblast and TSC/TPC.

In normal tendon, the tenocyte synthesizes a wide range of ECM proteins in a well-ordered structure. Among the most abundant of these proteins is type-I collagen. This protein is organized in a parallel arrangement providing a distinct hierarchical structure, which ultimately forms the tendon (Figure 1). The tenocyte secretes soluble trihelical tropocollagen that is assembled and cross-linked in parallel fibrillar arrays. Higher-order organization of these arrays is provided by the endotenon, which appears as a loose connective tissue layer that envelopes collagen fibrils to form tendon fascicles. Fascicles in turn are bundled together by the epitenon, a layer contiguous with the endotenon through which the microvasculature traverses and provides nutrients $(11,12)$. This multi-unit hierarchical structure aligns fiber bundles parallel with the long axis of the tendon and affords the tendon high tensile strength (1).

Normal tendon ECM is composed largely of collagen (predominantly type-I collagen, $\mathrm{COL}-\mathrm{I}^{1}$ ), which provides structural integrity and mechanical strength (13). A

\footnotetext{
${ }^{1}$ Please note that the abbreviation for the gene is given in italics and the abbreviation for the protein expressed by the gene is given in capital letters.
}

small amount of ground substances (Table 1 ) is not only important in fibrillogenesis but also provides tendon its high resistance behaviour to compressive and tensile forces (14). COL-I constitutes about $60 \%$ of the dry mass of the tendon and about $95 \%$ of the total collagen in tendon (15). The remaining $5 \%$ consists of type III and V collagens. In a normal tendon, type III collagen (COL-III) is mainly located in the endotenon and epitenon $(16,17)$. The ratio of COL-I to COL-III has been previously used as indicators of the tenogenic characteristics in tendon tissues and tenocyte cultures $(18,19)$. Other collagen (types II, VI, IX, X and XI) are present in trace amount in tendons (6). The ground substance of the tendon ECM network surrounding the collagen and tenocytes is composed of proteoglycans and several other small molecules (7). The proteoglycan content in a tendon (dry mass) is relatively lower than other musculoskeletal tissue (14). The content varies at different sites of the tendon and is dependant on the mechanical loading conditions, eg. tension vs. compression $(20-22)$ [ $6 \%$ in the compression region and $\sim 0.2 \%$ in the tensional region]. A summary of the types of proteoglycans present in tendon is presented in Table 2. Although normal mechanical function of tendon depends on the precise alignment of collagen fibrils, it is proteoglycans that regulate collagen fibrillogenesis. This is achieved via the interaction between the positively-charged groups of collagen fibers and the negatively-charged groups of the glycosaminoglycans (GAGs) in a proteoglycan molecule (14). This, indirectly affects a tendon's functionality. Members of the small-leucine-rich proteoglycan (SLRP) family (eg. decorin, biglycan, fibromodulin and lumican) bind to collagen fibrils and actively participate in fibrillogenesis (23). Depletion of biglycan and fibromodulin affects the TSP/TPC differentiation and impairs tendon formation in vivo (8). Other proteins, such as adhesive glycoproteins (eg. fibronectin and thrombospondin) are involved in binding the tenocytes to the collagen fibers 


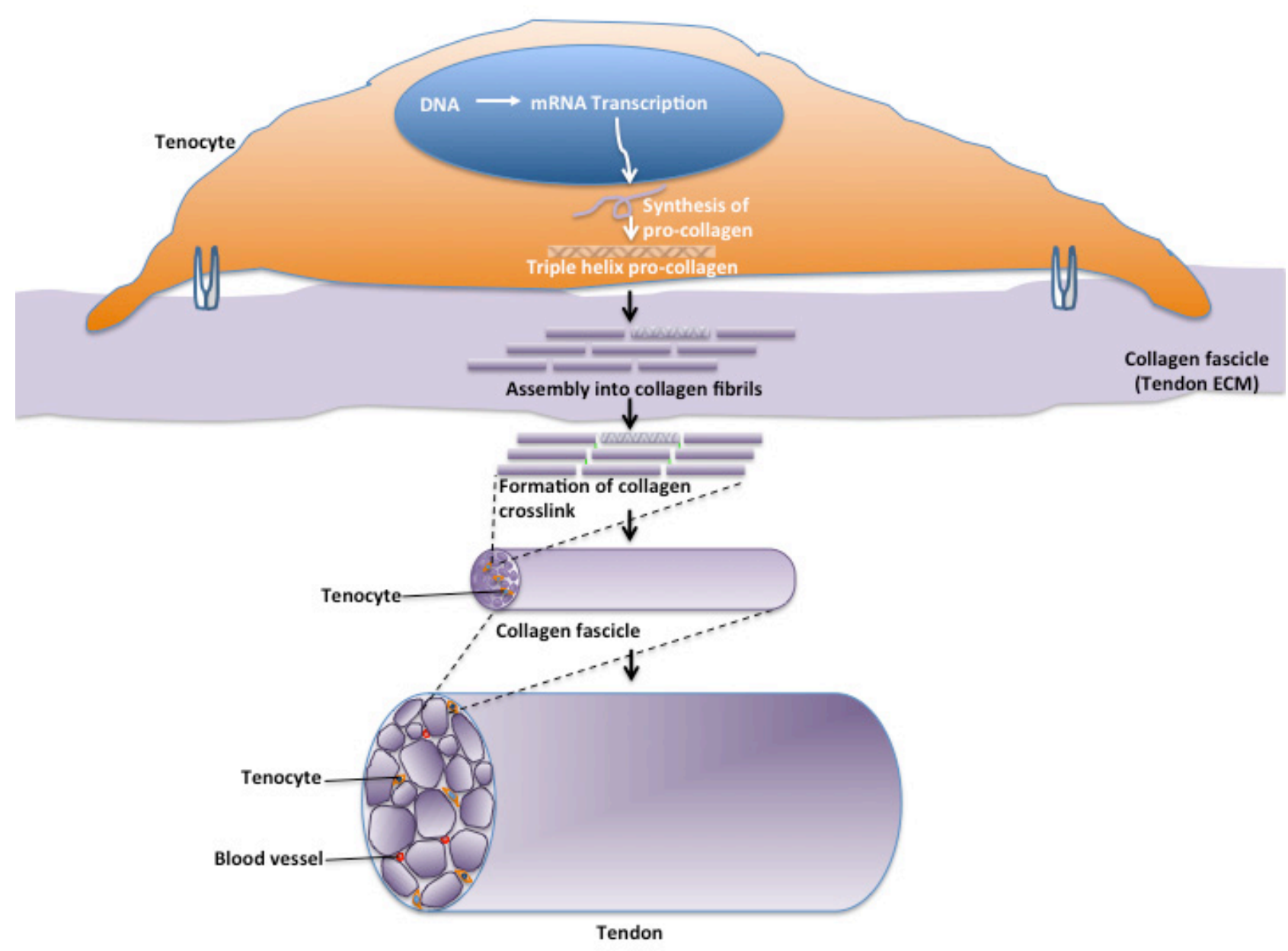

Figure 1: Schematic diagram of hierarchical structure of tendon (68).

The fibril is the smallest tendon structural unit; it consists largely of rod-like collagen molecules aligned end-to-end in a quarter staggered arrays. Fibers form the next level of tendon structure. Fibers are composed of collagen fibrils and are bound by endotenons. Fiber bundles form fascicles, and bundles of fascicles are enclosed by the epitenon. Tendons are also surrounded by a third layer of connective tissue called paratenon (not shown in this figure).

(24). These, are important in the repair and regeneration process in tendon (25-27). Apart from these ECM proteins, several polypeptide factors are important in regulating the expression of specific genes that are commonly found in tendons and the expression of these genes influences the ECM metabolism and subsequently modulates the composition and organization of the tendon ECM (Table 3).

\section{Early Tendon Development}

The formation of the musculoskeletal system from the somatic mesoderm requires the coordinated development of muscle, cartilage and tendon lineages. In the early somite development, muscle and cartilage emerge from two distinct compartments, the myotome and the sclerotome. This is in response to signals secreted from the surrounding tissues. As the somite matures, the tendon lineage is established within the dorsolateral sclerotome (or syndetome, the fourth somitic compartment (28)), which is adjacent to and beneath the myotome. The formation of a scleraxis $(S c x)$-expressing tendon progenitor (TP) population in the sclerotome is induced by a fibroblast growth factor (FGF) signal secreted from the myotome.

The FGF transcription effectors (Pea3 and Erm) are necessary for TP marker Scx expression in the somite to be expressed $(29,30)$. The domain of Scx expression, or the location of the syndetome, is dependent on the combined conditions of the restricted expression pattern of Pea3 and Erm within the anterior and posterior sclerotome, and the distances that FGFs secreted from the center of the myotome are able to travel. Brent and colleagues (2005) also suggested that the early myotome regulatory factors, Myf5 and Myod1 (previously known as MyoD) expressions are required for FGF protein expression in the myotome, which in turn is required for the induction 
Table 2: Summary of most abundant tendon proteoglycans.

\begin{tabular}{|l|l|l|}
\hline Class & Designation & Role in Tendon \\
\hline \multirow{3}{*}{ SLRP } & Decorin & $\begin{array}{l}\text { Binds to fibrillar collagen, inhibits collagen fibrillogenesis, binds TGF, } \\
\text { and EGF (70). }\end{array}$ \\
\cline { 2 - 3 } & Biglycan & Binds to fibrillar collagen, absent in avian species (23). \\
\cline { 2 - 3 } & Fibromodulin & $\begin{array}{l}\text { Binds to type I collagen, facilitates formation of mature large collagen } \\
\text { fibrils, modulation of tendon strength (71). }\end{array}$ \\
\cline { 2 - 3 } & Lumican & $\begin{array}{l}\text { Binds to type I collagen, inhibits size of collagen fibrils, modulation } \\
\text { of tendon strength (71). }\end{array}$ \\
\hline \multirow{2}{*}{ Modular (lectican) } & Aggrecan & $\begin{array}{l}\text { Linked to hyaluronan, provides resiliency, low levels in tensional } \\
\text { parts of tendon, high levels in compressed regions, particularly in } \\
\text { fibrocartilage (72). }\end{array}$ \\
\cline { 2 - 3 } & Versican & $\begin{array}{l}\text { Linked to hyaluronan, low levels in tensional parts of tendon, somewhat } \\
\text { higher levels in compressed regions, increases viscoelasticity, } \\
\text { maintains cell shape (73). }\end{array}$ \\
\hline
\end{tabular}

Table 3: Genes involved in tendon development and repair (Adapted from James et al., 2008) (74).

\begin{tabular}{|ll|}
\hline Gene & Function in development, repair or tissue regeneration \\
\hline Scleraxis $(S c x)$ & $\begin{array}{l}\text { Molecular regulator of tenocyte differentiation (75) and activate the Col-1a1 gene in } \\
\text { tendon fibroblast (76). }\end{array}$ \\
\hline Tenomodulin (TnMd) & A regulator of cell proliferation, differentiation and collagen fibril maturation (77). \\
\hline Tenascin C (Tnc) & $\begin{array}{l}\text { A mechano-responsive modulator of matrix formation expressed in high tensional } \\
\text { loading tissue such as tendons and ligaments (78). An ECM protein that is evident } \\
\text { during embryonic and tendon development (79). }\end{array}$ \\
\hline $\begin{array}{l}\text { Collagen I } \\
\text { (Col-I) }\end{array}$ & $\begin{array}{l}\text { Mature and highly organized collagen fibrils that allows tendon to withstand high } \\
\text { tensional loading (76). }\end{array}$ \\
\hline $\begin{array}{l}\text { Collagen III } \\
\text { (Col-III) }\end{array}$ & Early ECM collagen in wound repair (19,80). \\
\hline $\begin{array}{l}\text { Decorin (Dcn) and } \\
\text { aggrecan (Acan) }\end{array}$ & Proteoglycan interactions modulating collagen fibril orientation and alignment (81). \\
\hline Smad8 & Tenocyte differentiation, phenotype modulation and intracellular signaling (82). \\
\hline
\end{tabular}

of TP markers. In addition, they suggested that tendon and cartilage lineages arising from the sclerotome appear to be alternative and mutually exclusive, where the loss of chondrocyte differentiation results in an expanded somitic TP population. This causes the Sox9-expressing mesenchymal condensations to begin expressing tendon markers. It worth noting that when the differentiation of one cell fate is blocked, the other is adopted (30).

In contrast to the differentiation of axial tendons, that of the cartilages or tendons of the appendicular skeleton arises in situ. The initiation of tendon differentiation in the appendicular skeleton does not seem to require the presence of muscle (31). Nevertheless, the maintenance of distal tendons does require interaction with muscle because in the absence of muscle these tendons gradually degenerate (31). Based on the observation of Scx expression in the subectodermal location of the appendicular skeleton, it has been postulated that ectodermal signals might play a role in the occurrence of Scx-expressing TPs (32). However, the signals that initiate the expression of $S c x$ in the appendicular skeleton remain unknown.

In addition to FGF signaling for inducing sclerotomal cells to become tendon progenitor cells (TPC), transforming growth factor - $\beta$ (TGF $\beta$ ) signaling is also a potent inducer of $S c x$ both in organ culture and in cultured cells (33). This is said to be essential for the maintenance of the early TPC and has been suggested to mediate the recruitment of additional tendon cells by the adjacent muscles and 
cartilage condensations. This recruitment is to establish the connections of tendon primordia with these tissues, and it is an essential event for the subsequent differentiation and growth of mature tendons (33). In coordinating the cartilage and tendon differentiation in the developing limb mesenchyme, TGF-interacting factor, Tgif1, has been identified as one of the potential candidates which modulates the TGF $\beta$ signaling from chondrogenesis to fibrogenesis, and its expression pattern in the limb marks the developing tendons (34). This reprogramming of TGF $\beta$ signaling provokes down-regulation of Sox 9 and aggrecan and up-regulation of $S c x$ and tenomodulin through the Smad pathway (34). A recent review on the musculoskeletal assembly in the vertebrate embryo postulated that the induction and differentiation of TPCs occur in three distinct stages (Figure 2): induction, organization as well as aggregation and differentiation (35). In brief, the differentiation of tendon in the somite depends upon a combination of both activating and repressing signals from the other compartments of the somite.

However, little is known about other TGF- $\beta$ family members, in particular the bone morphogenetic protein

\section{A Induction}

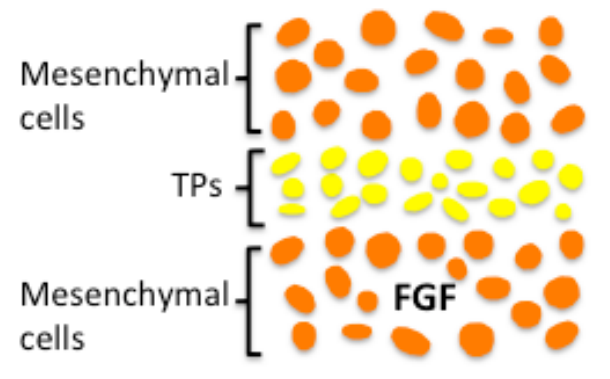

B Organization

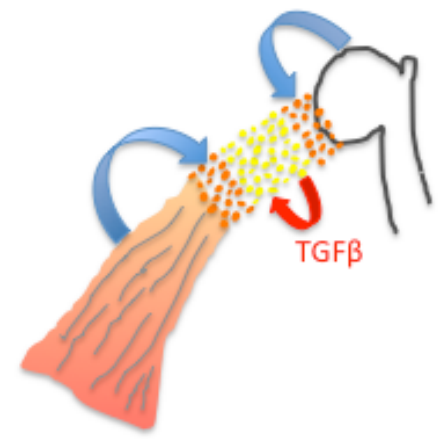

C Aggregation and differentiation

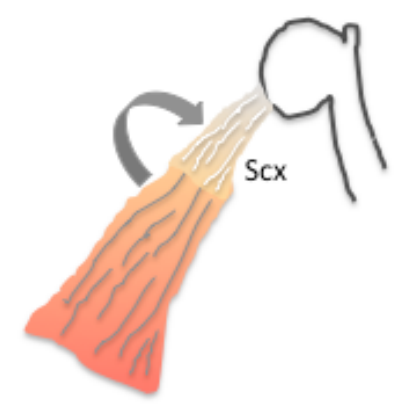

Figure 2:The three main stages and regulators of tendon induction and differentiation in vertebrate embryos (Adapted from Schweitzer et al. 2010) (35).

The Scx-expressing tendon progenitors (TPS) are represented in yellow and mesenchymal cells in orange to show the different stages of tendon induction and differentiation.

(a) Induction. The initial induction of Scx-expressing TPs is associated with FGF signaling, and the myotome in somites is the only identified source to date. In somites and digits, the progenitors are induced at or near their functional position between the myogenic and skeletogenic cells, but in the early limb bud and branchial arches the site of progenitor induction is not related to their final destination.

(b) Organization. At this stage, TPs throughout the embryonic body organize as loose cellular aggregations between the differentiating muscle and skeletal tissues. This transition depends on TGF $\beta$ signaling, which mediates the recruitment of additional TPs by the muscle and cartilage tissue to position and integrate the TPs with their interacting musculoskeletal tissues (blue arrows). In addition, TGF $\beta$ ligands expressed by the TPs are likely to contribute to the maintenance of the tenoblastic identity of the TPs (red arrow).

(c) Aggregation and differentiation. By E13.5, the TPs condense and organize into structurally distinct tendons that connect to the muscle and cartilage. In some, but not all tendons, tenocyte differentiation depends on Scx function. In most tissues, tendon differentiation depends on the presence of muscle (arrow), but the extensor and flexor tendons that extend into the autopod differentiate as structurally distinct tendons even in the absence of muscles.

(BMP) family members in musculoskeletal development. BMP5 is expressed in precise domains in the developing muscle masses and in the autopodial tendons. In the limb mesoderm, Smad and MAPK pathways act synergistically in the BMP pathway controlling limb development (36). Other BMP family members include growth and differentiation factor (GDF) isomers such as GDF5, -6 and -7 (also known as BMP 14, 13 and 12) have also been implicated in tendon development and healing (37-39). Mice deficient GDF5, -6 or -7 exhibit tendon ultrastructural, biological and/or biochemical abnormalities $(38,39)$, whereas exogenous delivery of these factors causes ectopic tendon formation
(40). In addition, as one of the earliest known markers of joint formation $(37,41)$, GDF5 dysregulation is strongly linked to various musculoskeletal malformations. GDF5 expression/activity is important in controlling different stages of skeletogenesis, in particular chondrogenesis in a GDF5 dose-dependent manner (42). In cartilage development, GDF5 signaling has a characteristic development pattern in pre-cartilage condensations and in the developing cartilaginous joints (37). Mutations in either GDF5 or its receptor BMP receptor 1B (BMPR1B) lead to similar skeletal malformation phenotypes, indicating that in chondrogenesis, GDF5 signaling seems to be exclusively 
mediated through BMPR-1B (43). Many developmental processes, including limb skeletogenesis, also require the segregation of signaling molecules into gradient or the functional compartmentalization of one cell type from another to generate information for differentiation and morphogenesis. Although GDF5 has functional roles in both tendon and cartilage development, it remains unclear whether GDF5 plays a role similar to that of FGF. It may be the case that tendon and cartilage lineages develop in an alternative and mutually exclusive manner through functional compartmentalization processes.

\section{TENDON DAMAGE AND REPAIR MECHANISM}

\section{A. Tendon Injury}

Tendon injuries, specifically at the shoulder, are a common cause of morbidity and contribute a significant health burden to society. It is defined as a loss of cells or ECM caused by trauma (44). Injury represents a failure of cell and matrix adaptation to a mechanical loading, in excess of the tolerance level, which can be repetitive or prolonged. In these circumstances, there is an inadequate response from the cells or tissues to the mechanical loading applied. In other words, tendon is injured when it is exposed to forces that damage it. Tendon injury at the shoulder can be as the result from forces that cause elongation of the tendon tissue extending into the micro- and macro-failure region. Under physiological circumstances, tendons function in the toe and linear region of the stress-strain curve. Repeated and prolonged load application has been shown to alter the stress-strain curve of the tendon tissue, where tendon injury may result from repeated loading into what would normally be the higher linear region of that curve (1). Rapid unloading has also been associated with tendon injury. Sudden force release is suggested to break interfibrillar adhesion because of shearing force within the tendon (7). In addition to forces that are too big for the tissue to withstand, tendon can also be injured when "normal" forces are applied. This occurrence can be seen in genetic disorders, aging, vascular changes, endocrine influences, nutritional deficiencies, inactivity, immobilization and exercise (45).

The cellular events in ruptured tendon (i.e. rotator cuff tendon) are closely related to the composition and integrity of ECM structure $(21,46,47)$. Tendon ECM transmits mechanical loads, stores and dissipates loading-induced elastic energy. Mechanical deformation in the ECM can transmit forces through tendon cell actin cytoskeleton and cause the remodeling of the actin cytoskeleton $(48,49)$. The cytoskeleton remodeling in turn controls the cell shape, affects cell motility and mediates various cellular functions including DNA and protein synthesis (50). Tendon cells sense mechanical force and convert them into biochemical signals via mechanotransduction mechanisms that ultimately lead to the physiological adaptiveness of tissue or conversely result in pathological changes.

\section{B. Normal Repair Mechanism}

Tendon injury will initiate attempts of tissue repair, which has been defined as replacement of damaged or lost cells and ECM by new cells or new matrices (44). In the natural healing process, tendon repair can be divided into different phases (Figure 3). Generally, it consists of an inflammatory phase, proliferation phase, differentiation phase and remodelling phase. In brief, the healing process starts with a hematoma, platelet activation and invasion of cells that form a granuloma. Inflammation after injury protects the body by eliminating and diluting harmful agents, preventing further injury, supplying large quantities of oxygen and nutrients needed for repair, and allowing the entry of clotting agents. Inflammation is triggered by several chemical mediators such as histamines, kinins, prostaglandins, complement, and lymphokines (51).

During the repair process, the clot formed during inflammation is transformed into granulation tissue. The circulating monocytes then differentiate into macrophages after entering the extravascular space. These macrophages are capable of digesting and removing the clot while providing a continuing source of growth factors, chemoattractants, and proteolytic enzymes as needed for tenocyte activation (44). The macrophage-derived growth factor and TGF $\beta$ cause the proliferation of tenoblasts originated in the epitenon (52). As tenoblasts infiltrate the wound, blood vessels are formed and facilitate RBC to carry oxygen and nutrients to the developing tissue. Tenoblasts rapidly produce COL-III, which is characterized by smaller fibrils lacking cross-links, which means that the tissue will be lacking tensile strength. At the later stage of this phase, the tenoblasts shift to produce COL-I. Initially, no crosslink occurs between the tropocollagen molecules. This facilitates the enzymatic breakdown and reorganization in the repaired tendon. Cross-links start to develop at 6-14 days post injury increasing tensile strength to the area of injury. At approximately 48 hours to 8 weeks post-injury, the disorganized collagen fibril deposition lies parallel to tensile forces within the tissue.

In the maturation and remodelling phase, cellularity and synthetic activity decreases in the tendon. However, the collagen production has been shown to be 15 times of normal tendon. The granulation tissue is supplanted by new collagen synthesis and deposition, as well as by remodelling myofibroblasts (which derived from the tenoblast that migrated from the edge of wound) that contract the matrix along the axis of the tendon. The ECM becomes more organized at this stage. Wound healing cells and their matrix exist in a dynamic reciprocity whereby cells deposit new matrix and that the matrix modulates gene expression and cell-matrix receptors (53). Through cell-cell and cell-matrix interactions, collagen fibrils align with tenocytes and join end-to-end with other fibrils in the wound and the margin via covalent crosslinks (2). Most cells (endothelial cells, macrophages and myofibroblasts) then enter apoptosis (programmed cell death), the ECM 


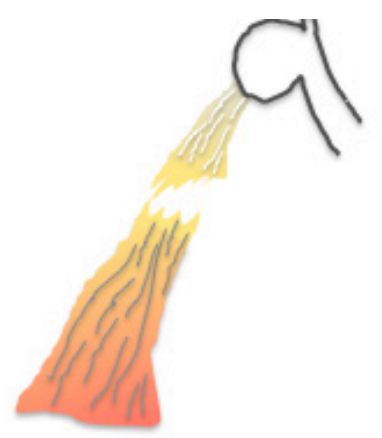

Torn tendon

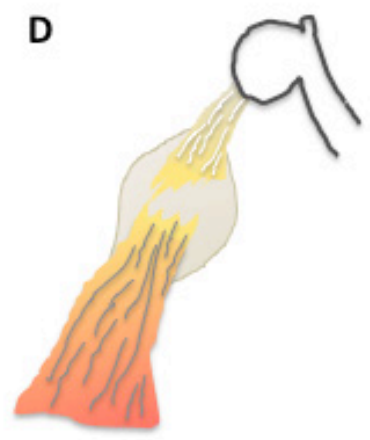

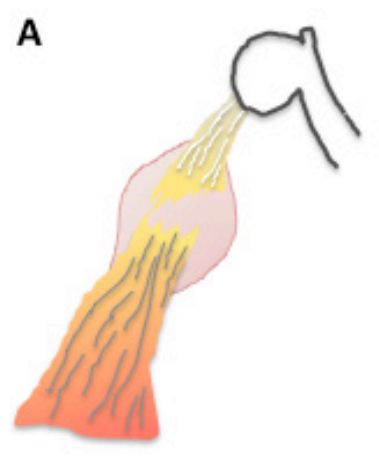
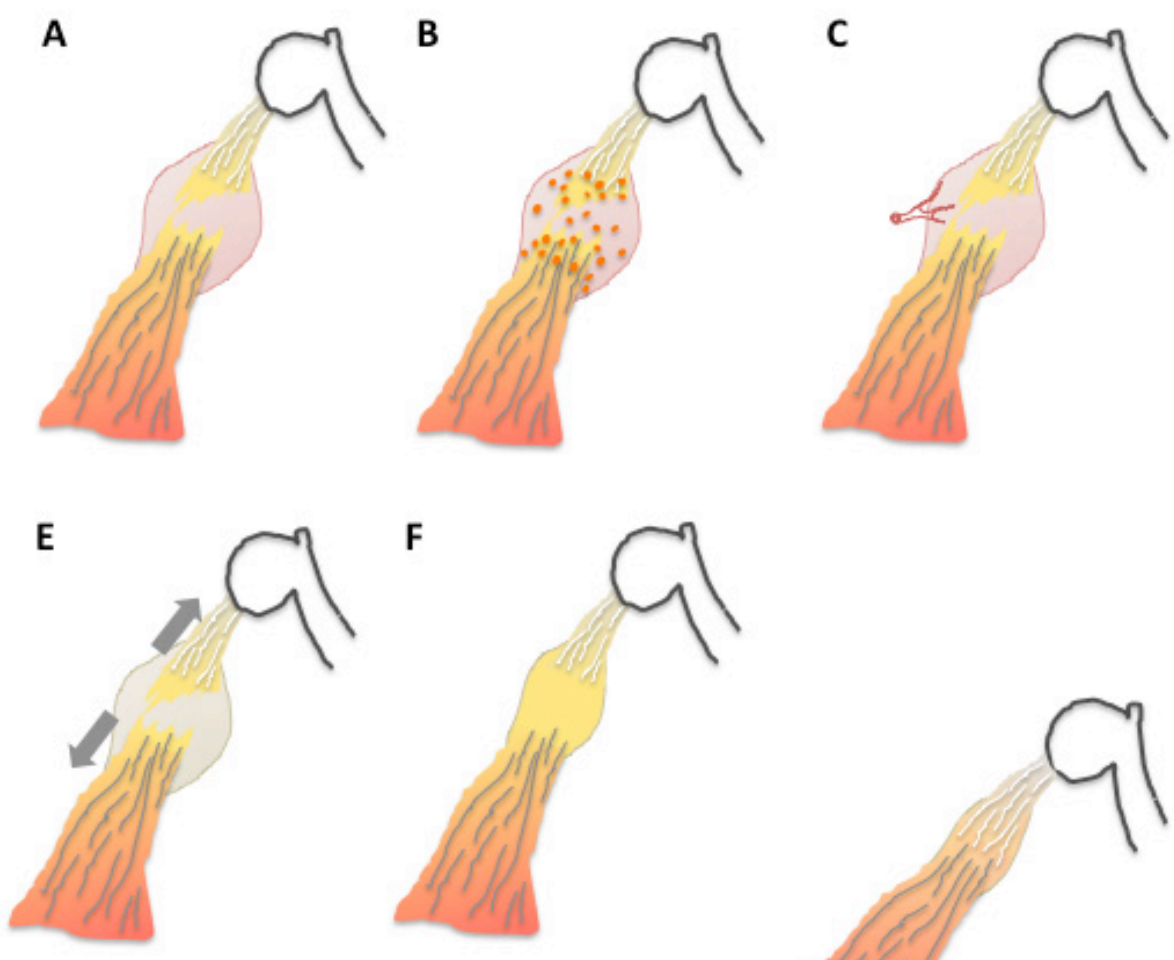

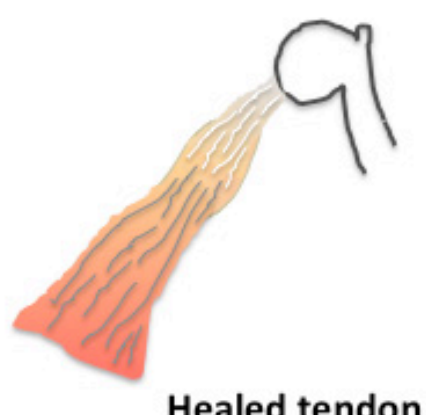

Healed tendon

Figure 3: Schematic diagram of tendon repair (69).

(a) Haematoma with platelet activation (inflammatory phase).

(b) Invasion of cells and proliferation of paratenon (proliferation phase).

(c) Vascular and neuronal ingrowth.

(d) Loose collageneous callus formation (differentiation phase).

(e) Mechanical stimulation.

(f) Maturation and remodeling (remodelling phase).

thereby undergoes a transition from a highly cellular granulation tissue to a less densely populated scar tissue (53). Consequently, tendons usually heal with fibrosis and scar tissue, which may regain only $70-80 \%$ of their original structural and biomechanical integrity for as long as oneyear-post injury. The healed tendon (with suboptimal tensile strength) is prone to reinjury, resulting in lifestyle changes with activity restriction. Poor vascularization (54) and histopathological changes (55) have been suggested as factors contributing to the resulting tendon thickening, fibrosis and being less resistant to tensile stress compared to its preinjured state. The origin of the cells responsible for repairing an injured tendon is controversial. Two mechanisms have been postulated: intrinsic and extrinsic. The former postulates that fibroblast populations come from the endotenon and epitenon, whereas the latter postulates that inflammatory cells and fibroblasts migrate in from surrounding tissues (56). However, a recent report suggested that intrinsic repair may require a progenitor class with predominant tendon marker expression, while extrinsic repair may involve a progenitor class recruited from perivascular cells of the peritenon (57). Tendon TSC/TPC decreases with age and alludes to its association with the age-related reduction in tendon repair as seen in rotator cuff tears (58). Molecular mechanisms controlling these events, either via tenocytes, tenoblast or/and TSC/ TPC, and whether a fully differentiated replacement tendon forms at these sites remains largely unclear. The understanding of molecular mechanism in tendon development could assist us in better understanding of tendon etiology and repair. 


\section{Surgical Repair and Cell Based Therapy in Tendon Healing}

Clinically, tendons are repaired or reconstructed using a variety of traditional and innovative methods or surgical techniques that vary with tendon location. These techniques, usually with application of tendon grafts (Table 4 ), demonstrate various degrees of success. In the light of current shortcomings of tendon repair, the current focus in tissue engineering research is to investigate a repair method which can restore the tissue defects with living cells, or a cell based therapy. A number of cell sources have been suggested, however each cell type demonstrate its own advantages and shortcomings as summarized in Table 5.

Table 4: The advantages and disadvantages of various type of tendon augmentation grafts.

\begin{tabular}{|c|c|c|c|}
\hline Graft Type & Source & Advantages & Disadvantages \\
\hline Autograft & Human & $\begin{array}{l}\text { No disease transmission risk. } \\
\text { No storage required. } \\
\text { No preservation problem. }\end{array}$ & $\begin{array}{l}\text { Donor site complication }(83,84) \text {. } \\
\text { Limited availability. }\end{array}$ \\
\hline Allograft & Human & $\begin{array}{l}\text { No donor site complications. } \\
\text { Availability. }\end{array}$ & $\begin{array}{l}\text { Immunogenicity problem ( } 85-87) \text {. } \\
\text { High risk of disease transmission (87). } \\
\text { Required proper storage or preservation } \\
\text { (88). }\end{array}$ \\
\hline Xenograft & Animal & As with allograft above. & $\begin{array}{l}\text { As with allograft above. } \\
\text { Ethical issue, i.e. inappropriate animal } \\
\text { source such as porcine derived tissue } \\
\text { graft. }\end{array}$ \\
\hline Prosthesis & Human or animal & As with allograft above. & $\begin{array}{l}\text { Low mechanical properties (often result } \\
\text { in failure of surgery). } \\
\text { Non-specific new tissue induction ability. } \\
\text { Induce inflammatory response and } \\
\text { rejection (89). }\end{array}$ \\
\hline Synthetic & $\begin{array}{l}\text { Chemical } \\
\text { compounds }\end{array}$ & $\begin{array}{l}\text { Stronger mechanical strength } \\
\text { and consistency in quality (89). }\end{array}$ & $\begin{array}{l}\text { Low biocompatibility. } \\
\text { Induce inflammatory response and } \\
\text { rejection (89). }\end{array}$ \\
\hline
\end{tabular}




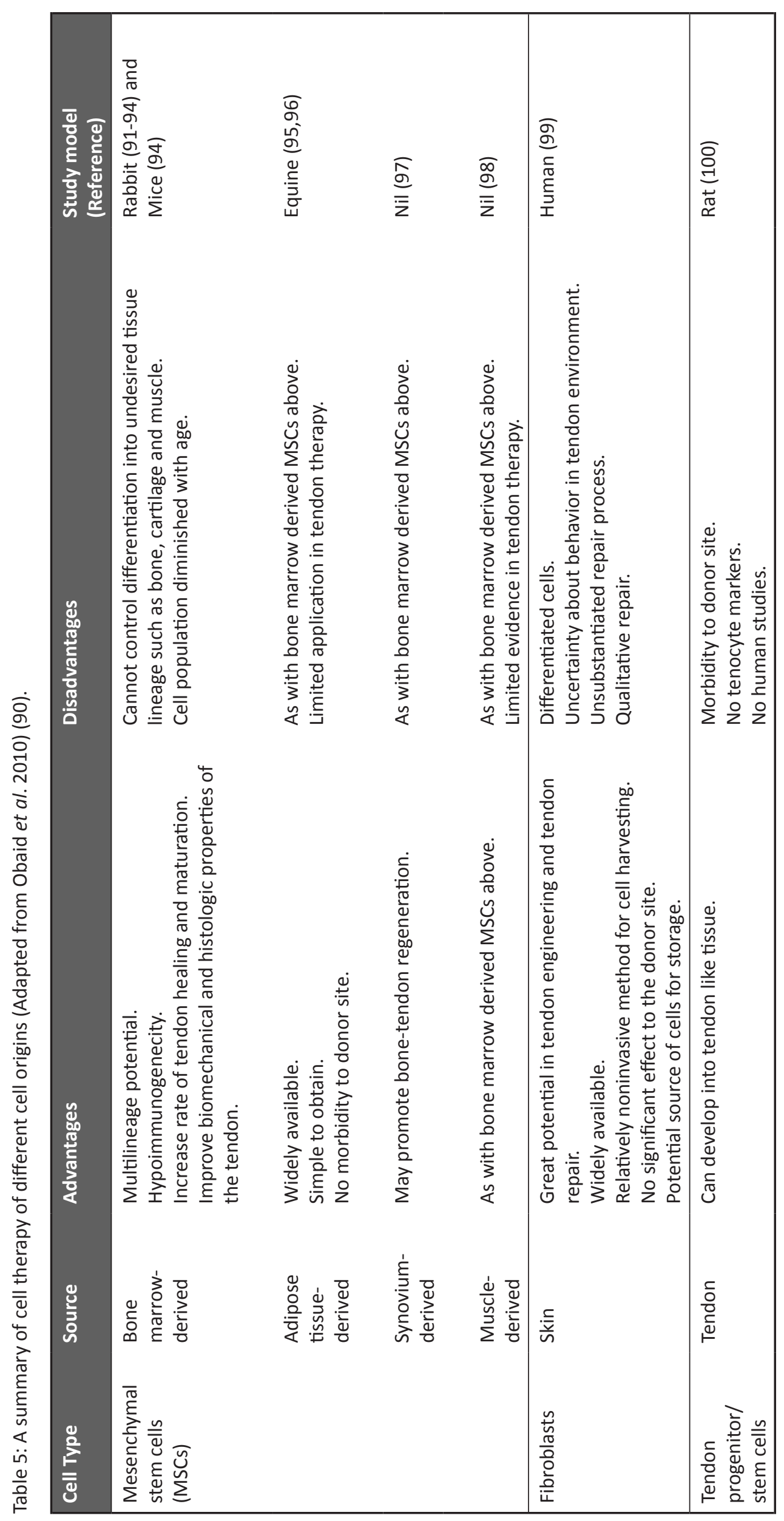




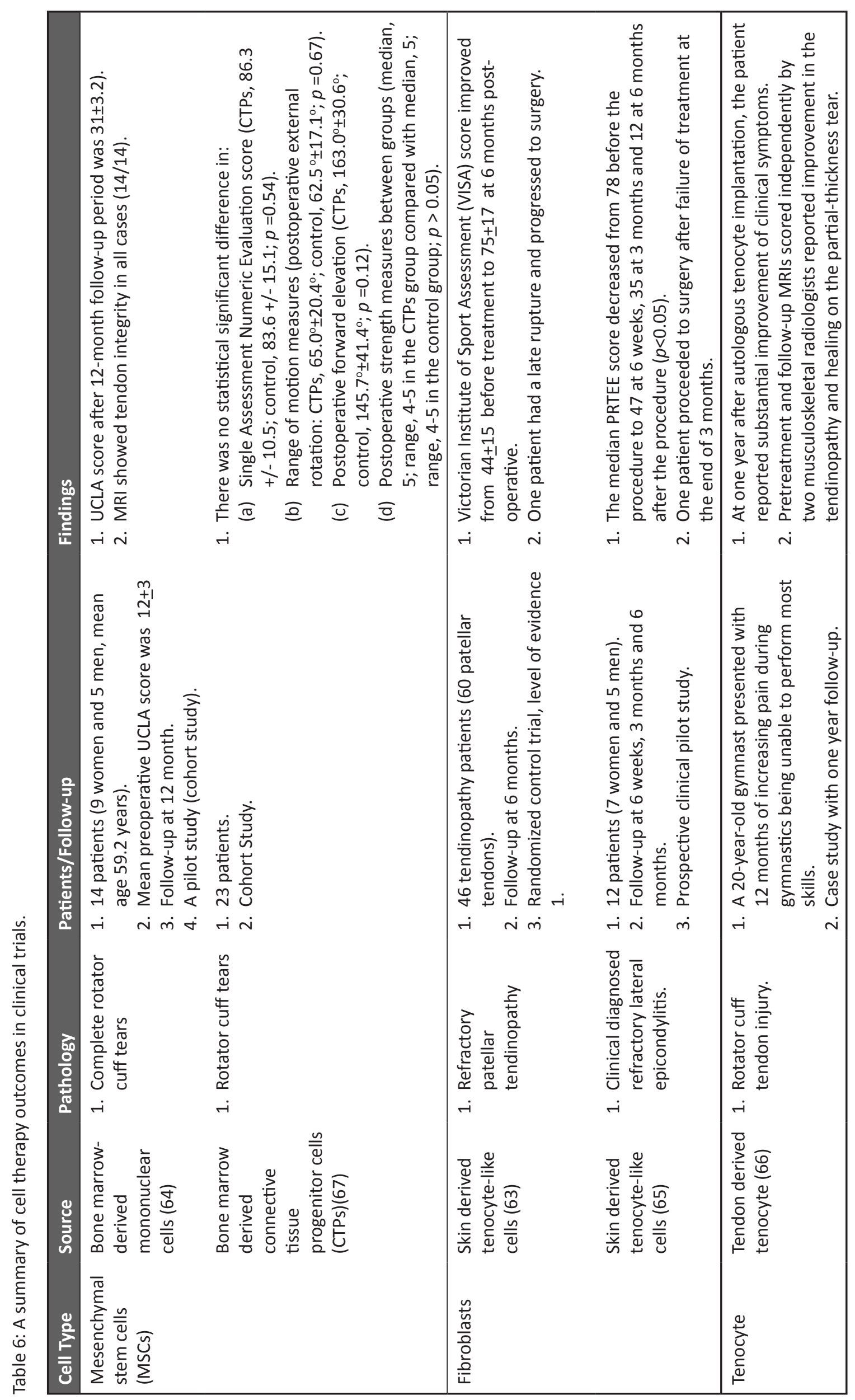


Cell based therapy seeks to enhance tissue repair by providing a cell and/or biological scaffold to a repair site in an attempt to elicit a healing response. In order to achieve this, investigators have seeded differentiated cells (mature cells or tenocytes) (59) and undifferentiated cells (mesenchymal stem cells) (60) on scaffolds to develop tissue engineered constructs. Various stimulations, either chemical (using growth factors and cytokines) (61) or mechanical (by stretching) (62), which can mimic the nature of normal tendon in vivo environment have been used to enhance the properties of the constructs. Advances in tendon tissue engineering approaches potentially yield a cell-based product that can markedly advance the repair of this soft tissue. Preclinical studies have shown the potential for cellular therapies to increase the tenocyte cell numbers and regenerate rather than repair tendon tissue (Table 5). To date, only 5 clinical studies of cell based therapy in tendons have been reported (Table 6). Of the five human studies reported, only one was randomized control trial, which showed the skin-derived tenocyte-like cells has a better potential than the autologous plasma to improve pain and function in patellar tendinopathy (63). Cohort studies showed that the bone marrow-derived mononuclear cells (64) and skin derived tenocyte-like cells (65) have a potential to improve rotator cuff tear and in lateral epicondylitis respectively. One case study using the ultrasound-guided autologous tenocyte implantation (ATI) showed an improve partial-thickness tear in a gymnast, who was able to return to national-level competition post-ATI (66). Nevertheless, one cohort study reported no significant improvement in the rotator cuff tear treated with bone marrow derived connective tissue progenitor cells (67).

Although current evidence shows that stem cells and tenocytes or tenocyte-like cells can have a positive effect on tendon healing, it remains to be elucidated whether the transplanted cells can help to produce tissue similar to the preinjury state. Questions remain whether tendon development events would re-occur and regenerate tendon tissue, when these cells (stem cells or TP cells) were transplanted to the defect site? In the course of cell-based therapy, would the implanted cells (stem cells, TP cells, tenoblast and tenocytes) together orchestrate cellular events of tendon regeneration? A better understanding in the cellular events involved in tendon development, differentiation and repair is needed in order to lead us to better outcomes for treating tendon injury. The use of adjuncts such as molecular signaling, mechanical stimulation, and other augmentation devices can potentially enhance stem cell therapy in the future.

\section{Acknowledgement}

Supported by HIR-MOHE research grant initiative, eScience Grant (12-02-03-2017), UMRG (RG093/09HTM), FRGS (FP004-2015A) and University of Malaya postgraduate student grant (PS167/2008C, PS360/2009B and PS219/2010A). This manuscript also represents a portion of a thesis submitted by Sik-Loo Tan to the Department of Orthopaedic Surgery, University of Malaya as partial fulfillment of the requirements for a PhD degree.

\section{References}

1. Wang JH. Mechanobiology of tendon. J Biomech. 2006; 39(9):1563-82.

2. Kjaer M. Role of extracellular matrix in adaptation of tendon and skeletal muscle to mechanical loading. Physiol Rev. 2004; 84(2):649-698.

3. Provenzano PP, Vanderby R, Jr. Collagen fibril morphology and organization: implications for force transmission in ligament and tendon. Matrix Biol. 2006; 25(2):71-84.

4. Amiel D, Frank C, Harwood F, Fronek J, Akeson W. Tendons and ligaments: a morphological and biochemical comparison. J Orthop Res. 1984; 1(3):257-65.

5. Kirkendall DT, Garrett WE. Function and biomechanics of tendons. Scand J Med Sci Sports. 1997;7(2):62-6.

6. Fukuta S, Oyama M, Kavalkovich K, Fu FH, Niyibizi C. Identification of types II, IX and X collagens at the insertion site of the bovine achilles tendon. Matrix Biol. 1998; 17(1):65-73.

7. Sharma P, Maffulli N. Tendon injury and tendinopathy: healing and repair. J Bone Joint Surg Am. 2005;87(1):187-202.

8. Bi Y, Ehirchiou D, Kilts TM, Inkson CA, Embree MC, Sonoyama W, et al. Identification of tendon stem/ progenitor cells and the role of the extracellular matrix in their niche. Nat Med. 2007; 13(10):1219-27.

9. Rui YF, Lui PP, Li G, Fu SC, Lee YW, Chan KM. Isolation and characterization of multipotent rat tendon-derived stem cells. Tissue Eng Part A. 2010; 16(5):1549-58.

10. Yin Z, Chen X, Chen JL, Shen WL, Hieu Nguyen TM, Gao $L$, et al. The regulation of tendon stem cell differentiation by the alignment of nanofibers. Biomaterials. 2010; 31(8):2163-75.

11. Fenwick SA, Hazleman BL, Riley GP. The vasculature and its role in the damaged and healing tendon. Arthritis Res. 2002; 4(4):252-60.

12. Boyer MI, Goldfarb CA, Gelberman RH. Recent progress in flexor tendon healing. The modulation of tendon healing with rehabilitation variables. $J$ Hand Ther. 2005; 18(2):80-5.

13. Benjamin M, Kaiser E, Milz S. Structure-function relationships in tendons: a review. J Anat. 2008; 212(3):211-28.

14. Yoon JH, Halper J. Tendon proteoglycans: biochemistry and function. J Musculoskelet Neuronal Interact. 2005; 5(1):22-34.

15. Evans JH, Barbenel JC. Structural and mechanical properties of tendon related to function. Equine Vet J. 1975; 7(1):1-8.

16. Becker U, Nowack H, Gay S, Timpl R. Production and specificity of antibodies against the aminoterminal region in type III collagen. Immunology. 1976; 31(1):57-65. 
17. Duance VC, Restall DJ, Beard H, Bourne FJ, Bailey AJ. The location of three collagen types in skeletal muscle. FEBS Lett. 1977; 79(2):248-52.

18. Yao L, Bestwick CS, Bestwick LA, Maffulli N, Aspden RM. Phenotypic drift in human tenocyte culture. Tissue Eng. 2006; 12(7):1843-9.

19. Maffulli N, Ewen SW, Waterston SW, Reaper J, Barrass V. Tenocytes from ruptured and tendinopathic achilles tendons produce greater quantities of type III collagen than tenocytes from normal achilles tendons. An in vitro model of human tendon healing. Am J Sports Med. 2000; 28(4):499-505.

20. Berenson MC, Blevins FT, Plaas AH, Vogel KG. Proteoglycans of human rotator cuff tendons. J Orthop Res. 1996; 14(4):518-25.

21. Riley GP, Harrall RL, Constant CR, Chard MD, Cawston TE, Hazleman BL. Tendon degeneration and chronic shoulder pain: changes in the collagen composition of the human rotator cuff tendons in rotator cuff tendinitis. Ann Rheum Dis. 1994; 53(6):359-66.

22. Waggett $A D$, Ralphs JR, Kwan AP, Woodnutt $D$, Benjamin M. Characterization of collagens and proteoglycans at the insertion of the human Achilles tendon. Matrix Biol. 1998; 16(8):457-70.

23. Vogel KG, Heinegard D. Characterization of proteoglycans from adult bovine tendon. J Biol Chem. 1985; 260(16):9298-306.

24. O'Brien M. Functional anatomy and physiology of tendons. Clin Sports Med 1992; 11(3):505-20.

25. Miller RR, McDevitt CA. Thrombospondin in ligament, meniscus and intervertebral disc. Biochim Biophys Acta. 1991; 1115(1):85-8.

26. Lawler J. The structural and functional properties of thrombospondin. Blood 1986; 67(5):1197-209.

27. Jozsa L, Kannus P, Balint JB, Reffy A. Three-dimensional ultrastructure of human tendons. Acta Anat (Basel). 1991; 142(4):306-12.

28. Brent AE, Schweitzer R, Tabin CJ. A somitic compartment of tendon progenitors. Cell. 2003; 113(2):235-48.

29. Brent AE, Tabin CJ. FGF acts directly on the somitic tendon progenitors through the Ets transcription factors Pea3 and Erm to regulate scleraxis expression. Development. 2004; 131(16):3885-96.

30. Brent AE, Braun T, Tabin CJ. Genetic analysis of interactions between the somitic muscle, cartilage and tendon cell lineages during mouse development. Development. 2005; 132(3):515-28.

31. Kardon G. Muscle and tendon morphogenesis in the avian hind limb. Development. 1998; 125(20):401932.

32. Liu CF, Aschbacher-Smith L, Barthelery NJ, Dyment $\mathrm{N}$, Butler D, Wylie C. What we should know before using tissue engineering techniques to repair injured tendons: a developmental biology perspective. Tissue Eng Part B Rev. 2011; 17(3):165-76.

33. Pryce BA, Watson SS, Murchison ND, Staverosky JA, Dunker N, Schweitzer R. Recruitment and maintenance of tendon progenitors by TGFbeta signaling are essential for tendon formation. Development. 2009; 136(8):1351-61.

34. Lorda-Diez Cl, Montero JA, Martinez-Cue C, GarciaPorrero JA, Hurle JM. Transforming growth factors beta coordinate cartilage and tendon differentiation in the developing limb mesenchyme. J Biol Chem. 2009; 284(43):29988-96.

35. Schweitzer R, Zelzer E, Volk T. Connecting muscles to tendons: tendons and musculoskeletal development in flies and vertebrates. Development. 2010; 137(17):2807-17.

36. Zuzarte-Luis V, Montero JA, Rodriguez-Leon J, Merino R, Rodriguez-Rey JC, Hurle JM. A new role for BMP5 during limb development acting through the synergic activation of Smad and MAPK pathways. Dev Biol. 2004; 272(1):39-52.

37. Settle SH, Jr., Rountree RB, Sinha A, Thacker A, Higgins $\mathrm{K}$, Kingsley DM. Multiple joint and skeletal patterning defects caused by single and double mutations in the mouse Gdf6 and Gdf5 genes. Dev Biol. 2003; 254(1):116-30.

38. Mikic B, Schalet BJ, Clark RT, Gaschen V, Hunziker EB. GDF-5 deficiency in mice alters the ultrastructure, mechanical properties and composition of the Achilles tendon. J Orthop Res. 2001; 19(3):365-71.

39. Mikic B, Rossmeier K, Bierwert L. Sexual dimorphism in the effect of GDF- 6 deficiency on murine tendon. J Orthop Res. 2009; 27(12):1603-11.

40. Wolfman NM, Hattersley G, Cox K, Celeste AJ, Nelson $\mathrm{R}$, Yamaji $\mathrm{N}$, et al. Ectopic induction of tendon and ligament in rats by growth and differentiation factors 5,6 , and 7 , members of the TGF-beta gene family. $J$ Clin Invest. 1997; 100(2):321-30.

41. Storm EE, Kingsley DM. GDF5 coordinates bone and joint formation during digit development. Dev Biol. 1999; 209(1):11-27.

42. Francis-West PH, Abdelfattah A, Chen P, Allen C, Parish J, Ladher R, et al. Mechanisms of GDF-5 action during skeletal development. Development. 1999; 126(6):1305-15.

43. Kotzsch A, Nickel J, Seher A, Sebald W, Muller TD. Crystal structure analysis reveals a spring-loaded latch as molecular mechanism for GDF-5-type I receptor specificity. EMBO J. 2009; 28(7):937-47.

44. Leadbetter WB. Cell-matrix response in tendon injury. Clin Sports Med. 1992; 11(3):533-78.

45. Hess GP, Cappiello WL, Poole RM, Hunter SC. Prevention and treatment of overuse tendon injuries. Sports Med. 1989; 8(6):371-84.

46. Wu B, Chen J, Rosa TD, Yu Q, Wang A, Xu J, et al. Cellular response and extracellular matrix breakdown in rotator cuff tendon rupture. Arch Orthop Trauma Surg. 2010; 131(3):405-411.

47. Riley GP, Harrall RL, Constant CR, Chard MD, Cawston $T E$, Hazleman BL. Glycosaminoglycans of human rotator cuff tendons: changes with age and in chronic rotator cuff tendinitis. Ann Rheum Dis. 1994; 53(6):367-76. 
48. Wang JH, Goldschmidt-Clermont P, Wille J, Yin FC. Specificity of endothelial cell reorientation in response to cyclic mechanical stretching. J Biomech. 2001; 34(12):1563-72.

49. Wang JH. Substrate deformation determines actin cytoskeleton reorganization: A mathematical modeling and experimental study. J Theor Biol. 2000; 202(1):33-41.

50. Janmey PA. Mechanical properties of cytoskeletal polymers. Curr Opin Cell Biol. 1991; 3(1):4-11.

51. Frank C, Shrive N, Hiraoka H, Nakamura N, Kaneda $\mathrm{Y}$, Hart D. Optimisation of the biology of soft tissue repair. J Sci Med Sport. 1999; 2(3):190-210.

52. Fyfe I, Stanish WD. The use of eccentric training and stretching in the treatment and prevention of tendon injuries. Clin Sports Med. 1992; 11(3):601-24.

53. Gurtner GC, Werner S, Barrandon Y, Longaker MT. Wound repair and regeneration. Nature. 2008; 453(7193):314-21.

54. Hegedus EJ, Cook C, Brennan M, Wyland D, Garrison JC, Driesner D. Vascularity and tendon pathology in the rotator cuff: a review of literature and implications for rehabilitation and surgery. BrJ Sports Med. 2010; 44(12):838-47.

55. Maffulli N, Longo UG, Maffulli GD, Khanna A, Denaro V. Achilles tendon ruptures in diabetic patients. Arch Orthop Trauma Surg. 2011; 131(1):33-8.

56. Boyer MI. Flexor tendon biology. Hand Clin. 2005; 21(2):159-66.

57. Mienaltowski MJ, Adams SM, Birk DE. Regional differences in stem cell/progenitor cell populations from the mouse achilles tendon. Tissue Eng Part $A$. 2013; 19(1-2):199-210.

58. Gulotta LV, Chaudhury S, Wiznia D. Stem cells for augmenting tendon repair. Stem Cells Int 2012; 2012:291431.

59. Cao Y, Liu Y, Liu W, Shan Q, Buonocore SD, Cui L. Bridging tendon defects using autologous tenocyte engineered tendon in a hen model. Plast Reconstr Surg. 2002; 110(5):1280-9.

60. Butler DL, Juncosa-Melvin N, Boivin GP, Galloway MT, Shearn JT, Gooch C, et al. Functional tissue engineering for tendon repair: A multidisciplinary strategy using mesenchymal stem cells, bioscaffolds, and mechanical stimulation. J Orthop Res. 2008; 26(1):1-9.

61. Lee JY, Zhou Z, Taub PJ, Ramcharan M, Li Y, Akinbiyi $\mathrm{T}$, et al. BMP-12 treatment of adult mesenchymal stem cells in vitro augments tendon-like tissue formation and defect repair in vivo. PLoS One. 2011; 6(3):e17531.

62. Morita Y, Mukai T, Ju Y, Watanabe S. Evaluation of Stem Cell-to-Tenocyte Differentiation By Atomic Force Microscopy to Measure Cellular Elastic Moduli. Cell Biochem Biophys. 2013; 66(1):73-80.

63. Clarke AW, Alyas F, Morris T, Robertson CJ, Bell J, Connell DA. Skin-derived tenocyte-like cells for the treatment of patellar tendinopathy. Am J Sports Med. 2011; 39(3):614-23.
64. Ellera Gomes JL, da Silva RC, Silla LM, Abreu MR, Pellanda R. Conventional rotator cuff repair complemented by the aid of mononuclear autologous stem cells. Knee Surg Sports Traumatol Arthrosc. 2012; 20(2):373-7.

65. Connell D, Datir A, Alyas F, Curtis M. Treatment of lateral epicondylitis using skin-derived tenocyte-like cells. Br J Sports Med. 2009; 43(4):293-8.

66. Wang AW, Bauer S, Goonatillake M, BreidahI W, Zheng $\mathrm{MH}$. Autologous tenocyte implantation, a novel treatment for partial-thickness rotator cuff tear and tendinopathy in an elite athlete. BMJ Case Rep 2013; 2013.

67. Mazzocca AD, McCarthy MB, Chowaniec DM, Cote MP, Arciero RA, Drissi H. Rapid isolation of human stem cells (connective tissue progenitor cells) from the proximal humerus during arthroscopic rotator cuff surgery. Am J Sports Med. 2010; 38(7):1438-47.

68. Silver FH, Freeman JW, Seehra GP. Collagen selfassembly and the development of tendon mechanical properties. J Biomech. 2003; 36(10):1529-53.

69. Aspenberg P. Stimulation of tendon repair: mechanical loading, GDFs and platelets. A mini-review. Int Orthop. 2007; 31(6):783-9.

70. Zhang G, Ezura Y, Chervoneva I, Robinson PS, Beason $\mathrm{DP}$, Carine ET, et al. Decorin regulates assembly of collagen fibrils and acquisition of biomechanical properties during tendon development. J Cell Biochem. 2006; 98(6):1436-49.

71. Iozzo RV, Murdoch AD. Proteoglycans of the extracellular environment: clues from the gene and protein side offer novel perspectives in molecular diversity and function. FASEB J. 1996; 10(5):598-614.

72. Rees SG, Flannery CR, Little CB, Hughes CE, Caterson $B$, Dent CM. Catabolism of aggrecan, decorin and biglycan in tendon. Biochem J 2000; 350 Pt 1:181-8.

73. Scott A, Lian O, Roberts CR, Cook JL, Handley CJ, Bahr $\mathrm{R}$, et al. Increased versican content is associated with tendinosis pathology in the patellar tendon of athletes with jumper's knee. Scand J Med Sci Sports. 2008;18(4):427-35.

74. James R, Kesturu G, Balian G, Chhabra AB. Tendon: biology, biomechanics, repair, growth factors, and evolving treatment options. J Hand Surg Am. 2008; 33(1):102-12.

75. Asou Y, Nifuji A, Tsuji K, Shinomiya K, Olson EN, Koopman $\mathrm{P}$, et al. Coordinated expression of scleraxis and Sox9 genes during embryonic development of tendons and cartilage. J Orthop Res. 2002;20(4):p. 827-33.

76. Lejard V, Brideau G, Blais F, Salingcarnboriboon R, Wagner G, Roehrl MH, et al. Scleraxis and NFATc regulate the expression of the pro-alpha1(I) collagen gene in tendon fibroblasts. J Biol Chem. 2007; 282(24):17665-75.

77. Docheva D, Hunziker EB, Fassler R, Brandau O. Tenomodulin is necessary for tenocyte proliferation and tendon maturation. Mol Cell Biol. 2005; 25(2):699-705. 
78. Mehr D, Pardubsky PD, Martin JA, Buckwalter JA. Tenascin-C in tendon regions subjected to compression. J Orthop Res. 2000; 18(4):537-45.

79. Chiquet-Ehrismann R, Tucker RP. Connective tissues: signalling by tenascins. Int J Biochem Cell Biol. 2004; 36(6):1085-9.

80. Williams IF, McCullagh KG, Silver IA. The distribution of types I and III collagen and fibronectin in the healing equine tendon. Connect Tissue Res. 1984; 12(3-4):211-27.

81. Sini P, Denti A, Tira ME, Balduini C. Role of decorin on in vitro fibrillogenesis of type I collagen. Glycoconj J. 1997; 14(7):871-4.

82. Towler DA, Gelberman RH. The alchemy of tendon repair: a primer for the (S)mad scientist. J Clin Invest. 2006; 116(4):863-6.

83. Comley AS, Krishnan J. Donor site morbidity after quadriceps tendon harvest for rotator cuff repair. Aust N Z J Surg. 1999; 69(11):808-10.

84. Aune AK, Holm I, Risberg MA, Jensen HK, Steen H. Four-strand hamstring tendon autograft compared with patellar tendon-bone autograft for anterior cruciate ligament reconstruction. A randomized study with two-year follow-up. Am J Sports Med. 2001; 29(6):722-8.

85. Minami A, Ishii S, Ogino T, Oikawa T, Kobayashi $\mathrm{H}$. Effect of the immunological antigenicity of the allogeneic tendons on tendon grafting. Hand. 1982; 14(2):111-9.

86. Nellas ZJ, Loder BG, Wertheimer SJ. Reconstruction of an Achilles tendon defect utilizing an Achilles tendon allograft. J Foot Ankle Surg. 1996; 35(2):144-8.

87. Nutton RW, McLean I, Melville E. Tendon allografts in knee ligament surgery. J $R$ Coll Surg Edinb. 1999;44(4):236-40.

88. Vangsness CT, Jr., Garcia IA, Mills CR, Kainer MA, Roberts MR, Moore TM. Allograft transplantation in the knee: tissue regulation, procurement, processing, and sterilization. Am J Sports Med 2003; 31(3):47481.

89. Chen J, Xu J, Wang A, Zheng M. Scaffolds for tendon and ligament repair: review of the efficacy of commercial products. Expert Rev Med Devices. 2009; 6(1):61-73.

90. Obaid H, Connell D. Cell therapy in tendon disorders: what is the current evidence? Am J Sports Med. 2010; 38(10):2123-32.
91. Awad HA, Butler DL, Boivin GP, Smith FN, Malaviya P, Huibregtse $B$, et al. Autologous mesenchymal stem cell-mediated repair of tendon. Tissue Eng. 1999; 5(3):267-77.

92. Harris MT, Butler DL, Boivin GP, Florer JB, Schantz EJ, Wenstrup RJ. Mesenchymal stem cells used for rabbit tendon repair can form ectopic bone and express alkaline phosphatase activity in constructs. J Orthop Res. 2004; 22(5):998-1003.

93. Chong AK, Ang AD, Goh JC, Hui JH, Lim AY, Lee EH, et al. Bone marrow-derived mesenchymal stem cells influence early tendon-healing in a rabbit achilles tendon model. J Bone Joint Surg Am. 2007; 89(1):7481.

94. Djouad F, Plence P, Bony C, Tropel P, Apparailly F, Sany $\mathrm{J}$, et al. Immunosuppressive effect of mesenchymal stem cells favors tumor growth in allogeneic animals. Blood. 2003; 102(10):3837-44.

95. Del Bue M, Ricco S, Ramoni R, Conti V, Gnudi G, Grolli $\mathrm{S}$. Equine adipose-tissue derived mesenchymal stem cells and platelet concentrates; their association in vitro and in vivo. Vet Res Comm. 2008; 32(1):51-55.

96. de Malttos Carvalho A, Alves ALG, de Oliveira PGG, Alvarez LEC, Amorim RL, Hussni CA, et al. Use of Adipose Tissue-Derived Mesenchymal Stem Cells for Experimental Tendinitis Therapy in Equines. J Equine Vet Sci 2011; 31:26-34.

97. Chen G, Zhang SX, Zhang ZZ. Over-expression of has2 in synovium-derived mesenchymal stem cells may prevent adhesions following surgery of the digital flexor tendons. Medic Hypothesis. 2011; 76(3):314316.

98. Rosenbaum AJ, Grande DA, Dines JS. The use of mesenchymal stem cells in tissue engineering. A global assessment. Organogenesis. 2008; 4(1):23-27.

99. Connell D, Datir A, Alyas F, Curtis M. Treatment of lateral epicondylitis using skin-derived tenocyte-like cells. Br J Sports Med. 2009; 43(4):293-298.

100. Gurkan UA, Cheng X, Kishore V, Uquillas JA, Akkus O. Comparison of morphology, orientation, and migration of tendon derived fibroblasts and bone marrow stromal cells on electrochemically aligned collagen constructs. J Biomed Mater Res A. 2010; 94(4):1070-9. 